\title{
Visual Outcomes at 12 Months in Patients Following Implantation of a Diffractive Multifocal Intraocular Lens
}

\author{
Mehmet Baykara • Yonca Aydin Akova • Osman Sevki Arslan • \\ Necdet Cinhuseyinoglu $\cdot$ Tamer Takmaz • Ahmet Gucukoglu • \\ Yildirim Beyazit Usta
}

To view enhanced content go to www.ophthalmology-open.com Received: December 26, 2014 / Published online: March 31, 2015

(c) The Author(s) 2015. This article is published with open access at Springerlink.com

\section{ABSTRACT}

Introduction: The aim of this study was to assess distance, intermediate, and near visual acuity, contrast sensitivity, and patient satisfaction outcomes of a multifocal intraocular lens (IOL).

Methods: This multicenter, prospective clinical study was conducted at seven study sites in

Electronic supplementary material The online version of this article (doi:10.1007/s40123-015-0032-4) contains supplementary material, which is available to authorized users.

M. Baykara $(\bowtie)$

Department of Ophthalmology, Uludag University, Bursa, Turkey

e-mail: mbaykara@uludag.edu.tr

Y. A. Akova

Department of Ophthalmology, Baskent University, Ankara, Turkey

Present Address:

Y. A. Akova

Department of Ophthalmology, Bayındır Hospital, Ankara, Turkey

O. S. Arslan

Department of Ophthalmology, Cerrahpasa Faculty of Medicine, Istanbul University, Istanbul, Turkey

N. Cinhuseyinoglu

Department of Ophthalmology, Okmeydani

Training and Research Hospital, Istanbul, Turkey
Turkey. Patients who underwent bilateral cataract removal and implantation of a diffractive, acrylic, hydrophobic, multifocal IOL (Acriva UD Reviol MFB 625; VSY Biotechnology, Istanbul, Turkey) were included. The uncorrected and best corrected distance visual acuities (UCDVA and BCDVA), uncorrected and best corrected intermediate visual acuities (UCIVA and BCIVA), and uncorrected and best corrected near visual acuities (UCNVA and BCNVA) were measured preoperatively and at postoperative 1,6 , and

\section{Present Address:}

N. Cinhuseyinoglu

Department of Ophthalmology, Bir Inci Eye Hospital, Istanbul, Turkey

\section{T. Takmaz}

Department of Ophthalmology, Ankara Ataturk

Training and Research Hospital, Ankara, Turkey

A. Gucukoglu

Department of Ophthalmology, Istanbul Faculty of Medicine, Istanbul University, Istanbul, Turkey

Y. B. Usta

Private Practice, Bursa, Turkey 
12 months. Distance and near visual acuity scores (VAS) contrast sensitivities were measured at these time points. Quality of life was evaluated by visual function-14 (VF-14) questionnaire.

Results: Two hundred eyes of 100 patients were included. Monocular and binocular visual acuities at all distances showed improvement at postoperative 12 months compared to preoperative measurements $(P<0.001)$. Monocular and binocular UCIVA and binocular BCIVA at postoperative 12 months were significantly improved compared to measurements at 1 month $\quad(P<0.001)$. Binocular contrast sensitivity at distance showed significant improvement from postoperative 1 month to postoperative 12 months, except for 3 cycles per degree (cpd; without glare) and $18 \mathrm{cpd}$ (with glare). VAS improved from 75.96 at postoperative 1 month to 76.85 at postoperative 12 months. VF-14 score was $98.2 \pm 4.6$.

Conclusion: The Acriva UD Reviol MFB 625 appears to provide a good level of distance and near visual acuity, quality of life, and patient satisfaction. Further studies with longer followup will provide valuable insight into the longterm stability of these visual outcomes.

Keywords: Contrast sensitivity; Intraocular lens; Visual acuity

\section{INTRODUCTION}

Monofocal intraocular lenses (IOLs) are traditionally used to replace the opacified natural lens that is removed during cataract surgery. Limitations of such IOLs, primarily a limited depth of focus providing clear vision either at distance or near, and dependence on reading spectacles for clear vision at all other viewing distances, have long been recognized $[1,2]$.

Refractive multifocal IOLs were developed to provide clear, spectacle-free vision over a wider range of distances. These IOLs distribute the incoming light to hit multiple focal points on the lens, consequently, creating multiple simultaneous retinal images. A disadvantage is that only one of these images is in focus at any given time. All other out-of-focus images may be detected as disturbances, including glare, halos, and poor contrast sensitivity [3]. In addition, some existing multifocal IOL designs distribute more light to the distance focus, compromising near visual acuity $[4,5]$.

In response to these limitations, diffractive multifocal IOL models have been developed. Unlike refractive multifocal IOLs, which have a series of focal zones for incoming light, diffractive IOLs have just two separate focal points: one for distance and one for near vision. Because of this design, diffractive multifocal IOLs may provide clear, spectacle-free distance and near vision, while avoiding the poor visual quality that typically arises from multiple foci [1].

We conducted this study to assess objective and subjective visual outcomes of patients implanted with the Acriva UD Reviol MFB 625 (VSY Biotechnology, Istanbul, Turkey), a hydrophobic, diffractive multifocal IOL.

\section{METHODS}

This multicenter, prospective clinical study involved patients scheduled to undergo cataract surgery between October 2010 and July 2011 at seven study sites. The study was conducted in accordance with the ethical standards stated in the Declaration of Helsinki, and all patients provided informed consents 
prior to the study. The study was approved by the Ethics Committee of the coordinator center which was Uludag University Medical Faculty, Bursa, Turkey.

All patients underwent bilateral phacoemulsification followed by implantation of a foldable, hydrophobic acrylic diffractive multifocal IOL (Acriva UD Reviol MFB 625; VSY Biotechnology, Istanbul, Turkey).

Acriva UD Reviol MFB 625 (Fig. 1) has active diffractive multifocal optic and is fully pupilindependent with 29 diffractive rings located in the anterior surface. The IOL is designed as single piece and aspheric and has UV photoprotection and square edge. Its optic size is $6.0 \mathrm{~mm}$ and total diameter is $12.5 \mathrm{~mm}$. Its haptic design is balance modified $\mathrm{C}$. The near add at the IOL plane is $+3.75 \mathrm{D}$ and the light distribution is $60 \%$ for distance and $40 \%$ between foci. Acriva UD Reviol MFB 625 distributes the light between far to near focus. With $2.0 \mathrm{~mm}$ pupil size, $72.1 \%$ of light is transmitted to far focus and $27.9 \%$ of light is distributed to near focus. With a pupil size of $5.0 \mathrm{~mm}, 60 \%$ of light is directed to far focus and $40 \%$ of light is transferred to near focus.

Cataract surgery on the second eye was performed 1 week after the first eye. Patients aged between 40 and 75 years, with bilateral

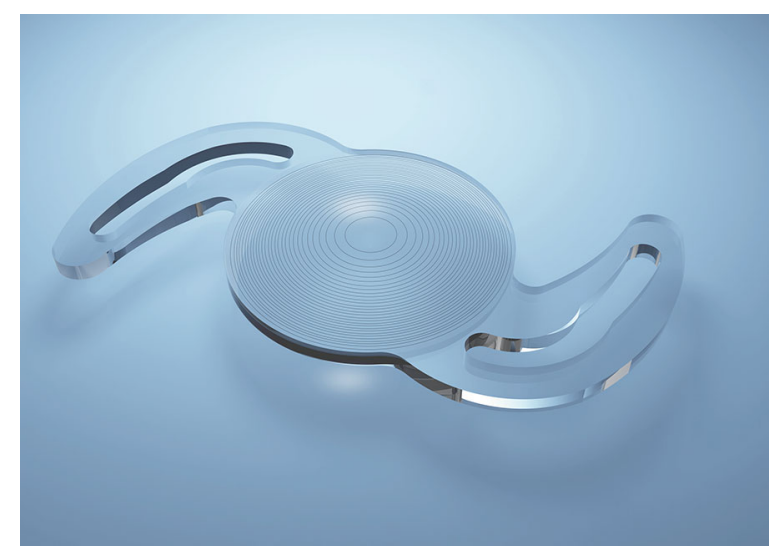

Fig. 1 Acriva UD Reviol MFB 625 cataract and who volunteered to return to the clinic for repeated assessments of visual outcomes, were included. Exclusion criteria included patients with unilateral pseudophakia, diabetes mellitus, macular disease, pupillary dysfunction, corneal astigmatism exceeding 0.75 diopters, those with occupations requiring high contrast sensitivity (e.g., surgeon or pilot), or those with occupations with increased risk of dysphotopsia (e.g., night time drivers).

Preoperatively, spherical and cylindrical refractive error, keratometry values, intraocular pressure (IOP), and pupil diameter under normal light conditions were measured and recorded. Optical coherence tomography was performed and pachymetry measurements were documented. Distance visual acuity was measured and recorded using the Early Treatment Diabetic Retinopathy Study (ETDRS) scale. Near (from $35 \mathrm{~cm}$ ) and intermediate visual acuities (from $60 \mathrm{~cm}$ ) were measured with the Jaeger card. Monocular and binocular uncorrected and corrected visual acuities at all three distances were assessed.

The study was conducted across seven centers. All centers adopted the same standardized surgical approach and surgical steps for cataract removal and IOL implantation. Before surgery, cataract density was measured based on the Emery and Little classification. Axial length was determined with immersion biometry (Bioline, Opticon Groningen, Netherlands). The SRK-II formula was used to determine the IOL power to reach the target refraction of emmetropia.

Phacoemulsification surgery was performed under topical anesthesia, through a $2.2 \mathrm{~mm}$ temporal clear corneal incision. Viscoelastic material was inserted into the anterior chamber and a central capsulorhexis, $5 \mathrm{~mm}$ in diameter, was created. The nucleus material was 
fragmented, aspirated, and irrigated. The Acriva UD Reviol MFB 625 multifocal IOL was inserted through the incision, using its injector system. After ensuring the correct positioning of the lens in the capsular bag, viscoelastic material was removed from the anterior chamber and back surface of the IOL $0.1 \mathrm{~mL}$ of cefuroxime was administered into the anterior chamber.

We measured the uncorrected and best corrected distance visual acuities (UCDVA and BCDVA), uncorrected and best corrected intermediate visual acuities (UCIVA and BCIVA), and uncorrected and best corrected near visual acuities (UCNVA and BCNVA) of patients preoperatively and at postoperative 1, 6 , and 12 months. Distance contrast sensitivity at four different spatial frequencies $(3,6,12$, and 18 cycles per degree; with and without glare) was also measured at these time points (using CSV 1000 HGT; Vector Vision, Ohio, USA). Near contrast sensitivity was assessed via Colenbrander mixed contrast reading cards [visual acuity score (VAS); VAS score ranges from 35 to 105]. Each line included five letters and one point was added for every letter read correctly.

Quality of life was evaluated by visual function-14 (VF-14) questionnaire, in which scores ranged from 0 to 100 . A score of $0-9$ reflected 'very severe impairment', 10-29 reflected 'severe impairment', 30-74 reflected 'moderate impairment', 75-92 reflected 'mild impairment', '93-98' reflected 'slight impairment', and 99-100 reflected 'no visual impairment'. A self-completion questionnaire assessing patient satisfaction with 12-month near, intermediate and distance visual acuities during the day and at nighttime was also completed. A scale of 1-4 was used, in which a score of 1 indicates 'very high satisfaction', 2 reflects 'good satisfaction', 3 indicates 'moderate satisfaction', and 4 indicates 'poor satisfaction'. Patients were also asked to state if they had any additional general complaints and photic phenomena such as halo and glare.

Additional evaluations performed during follow-up visits included measurement of IOP, refractive and keratometry values, central corneal thickness measurements by pachymeter, and slit lamp examination.

\section{Statistical Analysis}

We performed statistical analysis using the SPSS 15.0 program (IBM Corporation, Armonk, NY, USA). Descriptive statistics are presented as numbers and percentages for categorical variables, and mean, standard deviation, median, minimum and maximum values for numerical variables. Multiple comparisons for dependent groups for numerical variables without normal distribution were performed with Friedman test; comparisons of two dependent samples without normal distribution were performed with Wilcoxon signed-rank test. Wilcoxon signed-rank test with Bonferroni correction was used for post hoc comparisons. For categorical variables, comparison of two dependent samples was made using McNemar test. A $P$ value less than 0.05 was considered statistically significant.

\section{RESULTS}

Two hundred eyes of 100 patients (53\% male), with a mean age of $62.60 \pm 9.32$ years, were included in this study. All patients were followed up for a period of at least 12 months. Of the patients, $97 \%$ had visual loss in both eyes. The hardness of the cataractous lens was $2.7 \pm 0.8$, the axial length was $23.2 \pm 0.9 \mathrm{~mm}$, and the power of the IOL implanted was 
$21.3 \pm 2.4$ diopters. The visual characteristics of the patients at baseline and at 1, 6, and 12 months of surgery, are presented in Table 1 . The percentages of the patients within $0.5 \mathrm{D}$ of manifest spherical equivalent and $0.5 \mathrm{D}$ of cylinder are presented in Table 2.

Monocular and binocular visual acuities at all distances showed improvement at postoperative 12 months compared to preoperative measurements $(P<0.001$, for all $)$ The binocular UCDVA was $0.84 \pm 0.21 \mathrm{dec}$, UCIVA was J $1.14 \pm 0.39 \mathrm{dec}$, and UCNVA was J $1.04 \pm 0.19$ at postoperative 12 months. Monocular and binocular visual acuities recorded preoperatively and at 1,6 , and 12 months of surgery are presented in Table 3. Distribution of monocular and binocular visual acuities based on Snellen chart according to age groups is presented in Table 4 .

Binocular contrast sensitivity results with and without glare at $3,6,12$, and 18 cycles per degree (cpd) at 1, 6, and 12 months of surgery are presented in Table 5. Normal reading levels of contrast sensitivity were defined as 0-8 cpd.

Binocular distance contrast sensitivity values (with and without glare) for each spatial frequency showed significant improvement at postoperative 12 months compared with postoperative 1 month, except for $3 \mathrm{cpd}$ (without glare) and $18 \mathrm{cpd}$ (with glare).

There was no significant change in monocular and binocular near contrast sensitivity (VAS) values with time. Monocular

Table 1 Visual characteristics of the patients at baseline and at 1, 6, and 12 months of surgery

\begin{tabular}{lllllr}
\hline $\begin{array}{l}\text { Visual characteristics } \\
(\boldsymbol{n}=\mathbf{7 8})\end{array}$ & Preoperative & $\begin{array}{l}\text { Postoperative } \\
\text { 1 month }\end{array}$ & $\begin{array}{l}\text { Postoperative } \\
\mathbf{6} \text { months }\end{array}$ & $\begin{array}{l}\text { Postoperative } \\
\text { 12 months }\end{array}$ & $\boldsymbol{P}$ \\
\hline Spherical refraction & - & $-0.24 \pm 0.59$ & $-0.16 \pm 0.62$ & $-0.18 \pm 0.64$ & 0.163 \\
Cylindrical refraction & $-0.35 \pm 0.52^{\mathrm{b}, \mathrm{c}, \mathrm{d}}$ & $-0.64 \pm 0.50^{\mathrm{a}}$ & $-0.63 \pm 0.45^{\mathrm{a}}$ & $-0.61 \pm 0.51^{\mathrm{a}}$ & $<0.001$ \\
$C 1$ & $43.38 \pm 1.30^{\mathrm{b}, \mathrm{c}}$ & $43.19 \pm 1.26^{\mathrm{a}}$ & $42.89 \pm 2.80^{\mathrm{a}}$ & $43.23 \pm 1.29$ & 0.005 \\
$C 2$ & $43.81 \pm 1.49$ & $43.89 \pm 1.37^{\mathrm{c}}$ & $43.67 \pm 2.79^{\mathrm{b}}$ & $43.89 \pm 1.36$ & 0.028 \\
Intraocular pressure $(\mathrm{mmHg})$ & $14.92 \pm 2.29$ & $14.44 \pm 2.19$ & $14.38 \pm 2.29$ & $13.92 \pm 2.17$ & 0.065 \\
Central corneal thickness $(\mu \mathrm{m})$ & $552.56 \pm 32.9^{\mathrm{b}, \mathrm{c}}$ & $565.9 \pm 76.82^{\mathrm{a}, \mathrm{c}, \mathrm{d}}$ & $551.19 \pm 72.87^{\mathrm{a}, \mathrm{b}, \mathrm{d}}$ & $549.7 \pm 46.65^{\mathrm{b}, \mathrm{c}}$ & $<0.001$ \\
\hline
\end{tabular}

Values are presented as mean \pm standard deviation

$C 1$ horizontal axis of the cornea, $C 2$ vertical axis of the cornea

a Different from the preoperative value

b Different from postoperative 1 month

c Different from postoperative 6 months

d Different from postoperative 12 months

Table 2 Percentages of the patients within $0.5 \mathrm{D}$ of manifest spherical equivalent and $0.5 \mathrm{D}$ of cylinder

\begin{tabular}{|c|c|c|c|c|}
\hline$n=78$ & $\begin{array}{l}\text { Preoperative } \\
(-0.5 \mathrm{D})-(0.5 \mathrm{D})\end{array}$ & $\begin{array}{l}\text { Postoperative } \\
1 \text { month } \\
(-0.5 \mathrm{D})-(0.5 \mathrm{D})\end{array}$ & $\begin{array}{l}\text { Postoperative } \\
6 \text { months } \\
(-0.5 \mathrm{D})-(0.5 \mathrm{D})\end{array}$ & $\begin{array}{l}\text { Postoperative } \\
12 \text { months } \\
(-0.5 \mathrm{D})-(0.5 \mathrm{D})\end{array}$ \\
\hline Spherical refraction, $n(\%)$ & - & $54(69.2)$ & $56(71.8)$ & $51(65.4)$ \\
\hline Cylindrical refraction, $n(\%)$ & $56(71.8)$ & $41(52.6)$ & $40(51.3)$ & $36(46.2)$ \\
\hline
\end{tabular}


Table 3 Monocular and binocular visual acuities recorded preoperatively and at 1, 6, and 12 months of surgery

\begin{tabular}{|c|c|c|c|c|c|}
\hline & Preoperative & $\begin{array}{l}\text { Postoperative } \\
1 \text { month }\end{array}$ & $\begin{array}{l}\text { Postoperative } \\
6 \text { months }\end{array}$ & $\begin{array}{l}\text { Postoperative } \\
12 \text { months }\end{array}$ & $P$ \\
\hline \multicolumn{6}{|l|}{ UCDVA } \\
\hline Monocular (dec) & $0.12 \pm 0.27^{\mathrm{b}, \mathrm{c}, \mathrm{d}}$ & $0.75 \pm 0.21^{\mathrm{a}}$ & $0.75 \pm 0.22^{\mathrm{a}}$ & $0.76 \pm 0.21^{\mathrm{a}}$ & $<0.001$ \\
\hline Binocular (dec) & $0.38 \pm 0.19^{\mathrm{b}, \mathrm{c}, \mathrm{d}}$ & $0.82 \pm 0.21^{\mathrm{a}}$ & $0.84 \pm 0.21^{\mathrm{a}}$ & $0.84 \pm 0.21^{\mathrm{a}}$ & $<0.001$ \\
\hline \multicolumn{6}{|l|}{ BCDVA } \\
\hline Monocular (dec) & $0.45 \pm 0.42^{\mathrm{b}, \mathrm{c}, \mathrm{d}}$ & $0.90 \pm 0.13^{\mathrm{a}, \mathrm{c}}$ & $0.99 \pm 0.53^{\mathrm{a}, \mathrm{b}}$ & $0.93 \pm 0.12^{\mathrm{a}}$ & $<0.001$ \\
\hline Binocular (dec) & $0.59 \pm 0.21^{\mathrm{b}, \mathrm{c}, \mathrm{d}}$ & $0.94 \pm 0.16^{\mathrm{a}}$ & $0.97 \pm 0.12^{\mathrm{a}}$ & $0.97 \pm 0.13^{\mathrm{a}}$ & $<0.001$ \\
\hline \multicolumn{6}{|l|}{ UCNVA } \\
\hline Monocular (Jaeger) & $4.48 \pm 1.31^{\mathrm{b}, \mathrm{c}, \mathrm{d}}$ & $1.28 \pm 0.59^{\mathrm{a}}$ & $1.18 \pm 0.37^{\mathrm{a}}$ & $1.15 \pm 0.37^{\mathrm{a}}$ & $<0.001$ \\
\hline Binocular (Jaeger) & $4.16 \pm 1.44^{\mathrm{b}, \mathrm{c}, \mathrm{d}}$ & $1.13 \pm 0.44^{\mathrm{a}}$ & $1.09 \pm 0.29^{\mathrm{a}}$ & $1.04 \pm 0.19^{\mathrm{a}}$ & $<0.001$ \\
\hline \multicolumn{6}{|l|}{ BCNVA } \\
\hline Monocular (Jaeger) & $2.60 \pm 1.41^{\mathrm{b}, \mathrm{c}, \mathrm{d}}$ & $1.12 \pm 0.29^{\mathrm{a}}$ & $1.07 \pm 0.21^{a}$ & $1.06 \pm 0.23^{\mathrm{a}}$ & $<0.001$ \\
\hline Binocular (Jaeger) & $2.25 \pm 1.29^{\mathrm{b}, \mathrm{c}, \mathrm{d}}$ & $1.04 \pm 0.25^{\mathrm{a}}$ & $1.03 \pm 0.16^{a}$ & $1.01 \pm 0.11^{\mathrm{a}}$ & $<0.001$ \\
\hline \multicolumn{6}{|l|}{ UCIVA } \\
\hline Monocular (Jaeger) & $4.69 \pm 1.27^{\mathrm{b}, \mathrm{c}, \mathrm{d}}$ & $1.68 \pm 0.90^{\mathrm{a}, \mathrm{d}}$ & $1.54 \pm 0.80^{\mathrm{a}}$ & $1.38 \pm 0.63^{\mathrm{a}, \mathrm{b}}$ & $<0.001$ \\
\hline Binocular (Jaeger) & $4.44 \pm 1.20^{\mathrm{b}, \mathrm{c}, \mathrm{d}}$ & $1.38 \pm 0.71^{\mathrm{a}, \mathrm{d}}$ & $1.35 \pm 0.60^{\mathrm{a}, \mathrm{d}}$ & $1.14 \pm 0.39^{\mathrm{a}}$ & $<0.001$ \\
\hline \multicolumn{6}{|l|}{ BCIVA } \\
\hline Monocular (Jaeger) & $3.03 \pm 1.49^{\mathrm{b}, \mathrm{c}, \mathrm{d}}$ & $1.31 \pm 0.56^{\mathrm{a}, \mathrm{d}}$ & $1.24 \pm 0.55^{\mathrm{a}}$ & $1.17 \pm 0.42^{\mathrm{a}, \mathrm{b}}$ & $<0.001$ \\
\hline Binocular (Jaeger) & $2.77 \pm 1.44^{\mathrm{b}, \mathrm{c}, \mathrm{d}}$ & $1.18 \pm 0.51^{\mathrm{a}}$ & $1.17 \pm 0.44^{\mathrm{a}}$ & $1.06 \pm 0.25^{\mathrm{a}, \mathrm{b}, \mathrm{c}}$ & $<0.001$ \\
\hline
\end{tabular}

Values are presented as mean \pm standard deviation

$B C D V A$ best corrected distance visual acuities, $B C I V A$ best corrected intermediate visual acuities, $B C N V A$ best corrected near visual acuities, UCDVA uncorrected distance visual acuities, UCIVA uncorrected intermediate visual acuities, UCNVA uncorrected near visual acuities

${ }^{a}$ Different from the preoperative value

${ }^{b}$ Different from postoperative 1 month

${ }^{c}$ Different from postoperative 6 months

${ }^{d}$ Different from postoperative 12 months

and binocular near contrast sensitivity values at postoperative 1,6 , and 12 months are shown in Fig. 2.

Quality of life assessed at postoperative 12 months was very high, as reflected by a mean VF-14 score of $98.2 \pm 4.6$. Only five (2.3\%) patients reported halo and glare at postoperative 12 months. Patient satisfaction for distance, intermediate and near vision at postoperative 1,6 , and 12 months evaluated by the self-reporting questionnaire is presented in Table 6.

None of the patients developed posterior synechia and capsular fibrosis during the study period. Posterior capsular opacification (PCO) developed in six eyes at 6 months, and one eye required neodymium-doped yttrium aluminum garnet (Nd:YAG) capsulotomy; PCO occurred in 29 eyes at 12 months and 18 of them required Nd:YAG capsulotomy. 
Table 4 Distribution of monocular and binocular visual acuities based on Snellen chart according to age groups

$20 / 25$ and better

\begin{tabular}{|c|c|c|c|}
\hline All patients $n(\%)$ & Age groups & & \\
\hline & $<50$ years $n(\%)$ & $50-65$ years $n(\%)$ & $>65$ years $n(\%)$ \\
\hline
\end{tabular}

Binocular

$\begin{array}{lcccr}\text { UCDVA } & 56(71.8) & 7(70.0) & 27(84.4) & 22(61.1) \\ \text { UCNVA } & 75(96.2) & 10(100.0) & 32(100.0) & 33(91.7) \\ \text { UCIVA } & 68(87.2) & 9(90.0) & 29(90.6) & 30(83.3)\end{array}$

Monocular

\begin{tabular}{|c|c|c|c|c|}
\hline UCDVA & $50(64.1)$ & $7(70.0)$ & $23(71.9)$ & $20(55.6)$ \\
\hline UCNVA & $64(82.1)$ & $9(90.0)$ & $28(87.5)$ & $27(75.0)$ \\
\hline UCIVA & $52(66.7)$ & $8(80.0)$ & $23(71.9)$ & $21(58.3)$ \\
\hline
\end{tabular}

$U C D V A$ uncorrected distance visual acuities, $U C I V A$ uncorrected intermediate visual acuities, $U C N V A$ uncorrected near visual acuities

Table 5 Results of binocular contrast sensitivity with and without glare at 3, 6, 12, and 18 cpd at 1,6 , and 12 months of surgery

\begin{tabular}{llllr}
\hline Spatial frequency (cpd) & Postoperative 1 month & Postoperative 6 months & Postoperative 12 months & $\boldsymbol{P}$ \\
\hline 3 (without glare) & $1.52 \pm 0.19$ & $1.54 \pm 0.24$ & $1.54 \pm 0.23$ & 0.371 \\
3 (with glare) & $1.40 \pm 0.23^{\mathrm{b}, \mathrm{c}}$ & $1.45 \pm 0.25^{\mathrm{a}}$ & $1.46 \pm 0.21^{\mathrm{a}}$ & 0.008 \\
6 (without glare) & $1.62 \pm 0.23^{\mathrm{b}, \mathrm{c}}$ & $1.68 \pm 0.24^{\mathrm{a}}$ & $1.69 \pm 0.23^{\mathrm{a}}$ & $<0.001$ \\
6 (with glare) & $1.50 \pm 0.26^{\mathrm{b}, \mathrm{c}}$ & $1.57 \pm 0.25^{\mathrm{a}}$ & $1.59 \pm 0.26^{\mathrm{a}}$ & $<0.001$ \\
12 (without glare) & $1.22 \pm 0.26^{\mathrm{b}, \mathrm{c}}$ & $1.30 \pm 0.24^{\mathrm{a}}$ & $1.33 \pm 0.25^{\mathrm{a}}$ & $<0.001$ \\
12 (with glare) & $1.14 \pm 0.27^{\mathrm{b}, \mathrm{c}}$ & $1.21 \pm 0.27^{\mathrm{a}}$ & $1.25 \pm 0.28^{\mathrm{a}}$ & 0.005 \\
18 cpd (without glare) & $0.76 \pm 0.28^{\mathrm{b}, \mathrm{c}}$ & $0.82 \pm 0.31^{\mathrm{a}, \mathrm{c}}$ & $0.88 \pm 0.33^{\mathrm{a}, \mathrm{b}}$ & $<0.001$ \\
18 cpd (with glare) & $0.68 \pm 0.31$ & $0.74 \pm 0.31$ & $0.77 \pm 0.33$ & 0.051 \\
\hline
\end{tabular}

Values are presented as mean \pm standard deviation

cpd cycles per degree

a Different from postoperative 1 month

b Different from postoperative 6 months

c Different from postoperative 12 months

\section{DISCUSSION}

The wide range of focus and depth of focus provided by multifocal IOLs can be compromised by the limited visual quality often experienced by patients implanted with these IOLs [1]. Diffractive multifocal IOLs, such as the Acriva UD Reviol MFB 625, create 2 focal points, to assist smooth transition when viewing images at different focal zones. This aims to reduce the photic phenomena like halos and glare. It was reported by Elzawawi et al. [6] that near and distance visual acuities achieved with a diffractive multifocal IOL were found 


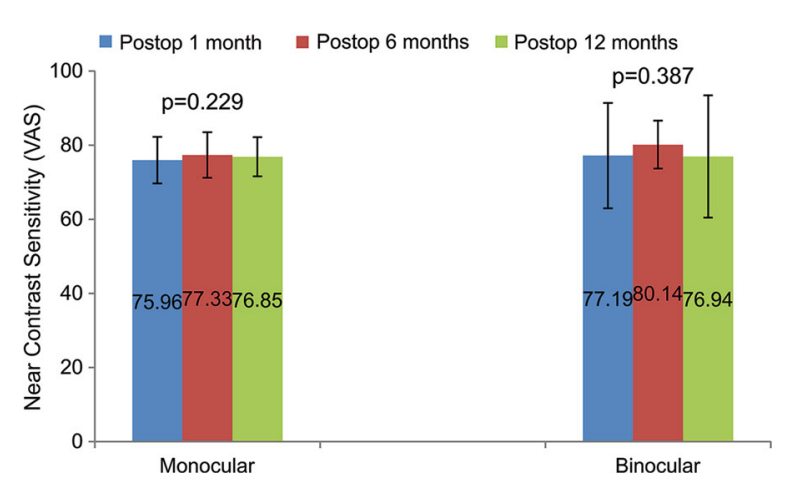

Fig. 2 Results of monocular and binocular near contrast sensitivity at postoperative 1, 6, and 12 months. Postop postoperative, $V A S$ visual acuity score

better compared to those achieved with a refractive multifocal IOL.

The findings of the current study suggest that the Acriva UD Reviol MFB 625 IOL improves patient visual acuity at all distances, near and distance contrast sensitivity, quality of life and patient satisfaction by 12 months after implantation.

The Acriva UD Reviol MFB 625 has a near addition of $+3.75 \mathrm{D}$ with a light distribution of $60 \%$ for distance focus and $40 \%$ for near focus. The current study findings showed that patients implanted with this IOL experienced a gradual improvement in mean monocular and binocular visual acuities at each successive visit. The level of visual acuity achieved in the current study is noticeably better than that reported by similar studies involving refractive multifocal IOLs. For example, in a study by Steinert et al. [4] 80.0\% of patients achieved a UCNVA above J3 and in the current study, $82.8 \%$ of the patients achieved a UCNVA of J1 or better by the twelfth postoperative month. In a study by Can et al. [7], in which visual outcomes with two diffractive multifocal IOLs (the Acriva UD Reviol MFM 611 and Acri Lisa 366D) were compared, distance and near visual acuities were found to be similar with both IOLs. Intermediate vision, however, was better with the Acriva UD Reviol MFM 611 IOL. There is a difference between two multifocal IOL model Reviol MFB 625 and Reviol MFM 611 in terms of haptic design. Reviol MFB 625 is designed by Balance $\mathrm{C}$ haptic structure which has a hole between two arms both front and back haptic. Balance $\mathrm{C}$ design is known to have more resistance to possible pressure from capsular bag. Acriva UD Reviol MFM 611 is plate design which is suitable for micro-incision cataract surgery.

The defocus curve was not investigated in the present study. However, the defocus curve of Acriva Reviol BB MF 613 and BB MFM 611 was investigated and compared with Acrysof Restor SN6AD1 and SN6AD3 in Wang et al.'s [8] study. A defocus curve was created with different levels of defocus and no difference was observed among the three groups at a viewing distance range of $67 \mathrm{~cm}$ and beyond in that study.

Contrast sensitivity measurements offer an objective measure of quality of vision. The present study did not have an adequate control group. For this reason, we compared the results with previous study results. In Can et al.'s [7] study, the clinical results of 2 diffractive multifocal IOLs, Acriva Reviol MFM 611 and Acri.Lisa 366D, were compared and stated that although differences in mesopic contrast sensitivity with glare and without glare between the 2 IOLs were not statistically significant, the results were better with the Acriva Reviol MFM 611 IOL. Both distance and near contrast sensitivity were assessed in a multifocal versus monofocal IOL study by Montés-Micó et al. [9]. Distance contrast sensitivity was better with a monofocal than multifocal IOL during the first 3 months after surgery. However, contrast sensitivity significantly improved, especially after the third month, reaching the same level as that 
Table 6 Patient satisfaction for distance, intermediate, and near vision at 1, 6, and 12 months of surgery

\section{Postoperative 1 month}

Postoperative 6 months

Postoperative 12 months

$\boldsymbol{P}$

Distance

Home

$\begin{array}{lllll}\text { Monocular } & 1.71 \pm 0.58^{\mathrm{c}} & 1.63 \pm 0.62^{\mathrm{c}} & 1.46 \pm 0.57^{\mathrm{a}, \mathrm{b}} & 0.002 \\ \text { Binocular } & 1.53 \pm 0.55^{\mathrm{c}} & 1.45 \pm 0.53 & 1.36 \pm 0.54^{\mathrm{a}} & 0.022 \\ \text { Sunlight } & & & & 0.002 \\ \text { Monocular } & 1.73 \pm 0.60^{\mathrm{c}} & 1.72 \pm 0.63^{\mathrm{c}} & 1.52 \pm 0.56^{\mathrm{a}, \mathrm{b}} & 0.566 \\ \text { Binocular } & 1.55 \pm 0.62 & 1.55 \pm 0.55 & 1.48 \pm 0.55 & 0.002 \\ \text { Night } & & & & 1.58 \pm 0.55^{\mathrm{a}, \mathrm{b}} \\ \text { Monocular } & 1.78 \pm 0.63^{\mathrm{c}} & 1.73 \pm 0.57^{\mathrm{c}} & 1.55 \pm 0.55 & 0.467 \\ \text { Binocular } & 1.61 \pm 0.57 & 1.60 \pm 0.54 & & \end{array}$

Near

Home

$\begin{array}{lllll}\text { Monocular } & 1.59 \pm 0.50^{\mathrm{c}} & 1.52 \pm 0.54^{\mathrm{c}} & 1.38 \pm 0.48^{\mathrm{a}, \mathrm{b}} & 0.001 \\ \text { Binocular } & 1.49 \pm 0.50^{\mathrm{c}} & 1.44 \pm 0.50 & 1.34 \pm 0.48^{\mathrm{a}} & 0.016 \\ \text { Sunlight } & & & & <0.001 \\ \text { Monocular } & 1.61 \pm 0.53^{\mathrm{c}} & 1.51 \pm 0.54^{\mathrm{c}} & 1.37 \pm 0.49^{\mathrm{a}, \mathrm{b}} & 0.008 \\ \text { Binocular } & 1.47 \pm 0.50^{\mathrm{c}} & 1.44 \pm 0.50^{\mathrm{c}} & 1.31 \pm 0.47^{\mathrm{a}, \mathrm{b}} & <0.001 \\ \text { Night } & & & & 1.39 \pm 0.52^{\mathrm{a}, \mathrm{b}} \\ \text { Monocular } & 1.64 \pm 0.55^{\mathrm{c}} & 1.58 \pm 0.53^{\mathrm{c}} & 1.34 \pm 0.50^{\mathrm{a}, \mathrm{b}} & 0.001 \\ \text { Binocular } & 1.55 \pm 0.57^{\mathrm{c}} & 1.52 \pm 0.55^{\mathrm{c}} & & \end{array}$

Intermediate

Home

\begin{tabular}{|c|c|c|c|c|}
\hline Monocular & $1.67 \pm 0.54^{c}$ & $1.65 \pm 0.52^{c}$ & $1.40 \pm 0.52^{\mathrm{a}, \mathrm{b}}$ & $<0.001$ \\
\hline Binocular & $1.60 \pm 0.57^{\mathrm{c}}$ & $1.49 \pm 0.55$ & $1.36 \pm 0.54^{\mathrm{a}}$ & 0.001 \\
\hline \multicolumn{5}{|l|}{ Sunlight } \\
\hline Monocular & $1.74 \pm 0.57^{\mathrm{c}}$ & $1.61 \pm 0.60^{c}$ & $1.47 \pm 0.58^{\mathrm{a}, \mathrm{b}}$ & $<0.001$ \\
\hline Binocular & $1.57 \pm 0.52^{c}$ & $1.51 \pm 0.60$ & $1.38 \pm 0.54^{\mathrm{a}}$ & 0.006 \\
\hline \multicolumn{5}{|l|}{ Night } \\
\hline Monocular & $1.77 \pm 0.62^{c}$ & $1.71 \pm 0.58^{c}$ & $1.46 \pm 0.57^{\mathrm{a}, \mathrm{b}}$ & $<0.001$ \\
\hline Binocular & $1.64 \pm 0.61^{\mathrm{c}}$ & $1.60 \pm 0.61^{\mathrm{c}}$ & $1.38 \pm 0.54^{\mathrm{a}, \mathrm{b}}$ & $<0.001$ \\
\hline
\end{tabular}

Values are presented as mean \pm standard deviation

a Different from postoperative 1 month

b Different from postoperative 6 months

c Different from postoperative 12 months 
achieved with the monofocal IOL by postoperative 6 months, at all spatial frequencies.

A study by Akcay et al. [10] compared the contrast sensitivity achieved with the multifocal Acriva UD Reviol and monofocal AcrySof IOLs. Findings showed no significant difference in distance contrast sensitivity between the two groups. At 12 and $18 \mathrm{cpd}$, Akcay et al. [10] found better contrast sensitivity values in those implanted with the Acriva UD Reviol than those implanted with the AcrySof IOL. The findings from the current study showed that normal levels of contrast sensitivity were observed throughout the follow-up period. A steady improvement was observed over the first twelve postoperative months. This indicates that the Acriva UD Reviol MFB 625 provides good light transmission, which may be due to its diffractive design. There was a high level of patient satisfaction with visual outcomes; only $2.3 \%$ of the patients reporting glare and halos. In the present study, contrast sensitivity values, with and without glare, were all within the normal limits during the follow-up period. In many other studies including diffractive and refractive multifocal IOLs, similar results were reported [8, 11-13]. Further studies with longer follow-up are required to determine the longterm stability of these results.

The Acriva UD Reviol MFB 625 design has a $360^{\circ}$ sharp square edge to minimize the risk of PCO. Serious PCO that required ND: YAG capsulotomy developed in 18 eyes. No other postoperative complications were noted. Biber et al. [14] compared the incidence of PCO and Nd:YAG laser capsulotomy rates of 3 IOL types. PCO and Nd:YAG laser capsulotomy rates in 3 AcrySof IOLs were as follows, respectively, in ReSTOR SN60D3, $42.7 \%$ and $25.3 \%$, in Natural SN60AT, $28.0 \%$ and $17.3 \%$, and in SN60WF,
14.7\% and 4.0\%. In another study with AcrySof ReSTOR and ReZoom IOLs, PCO rates were 54\% [15]. Martiano and Cochener [16] performed Nd:YAG laser posterior capsulotomy for PCO in $52 \%$ of high myopic eyes with multifocal IOLs. The effect of Nd:YAG laser posterior capsulotomy for PCO on refraction was investigated by Vrijman et al. [17]. They concluded that in most cases, Nd:YAG laser capsulotomy in patients with multifocal IOL's did not change the refraction. In the present study, no complications were observed after Nd:YAG laser posterior capsulotomy and this procedure did not change the refraction.

The current study was limited by the absence of a comparative group implanted with a refractive multifocal IOL. Such a group of patients would have allowed a direct comparison of visual outcomes with refractive and diffractive multifocal IOLs. In doing so, the findings may have revealed the impact of different IOL designs on visual disturbances and contrast sensitivity. Researchers will benefit from additional studies of a similar design in which visual quality outcomes with different types of diffractive multifocal IOLs are assessed. This will provide more conclusive evidence about the contribution of IOL design to the visual outcomes. Additional longer and larger scale studies will also be helpful in determining the validity of the current findings and assessing if the outcomes achieved in the current study persist in the long term.

\section{CONCLUSION}

Bilateral implantation of a diffractive multifocal IOL appears to produce good 12-month visual acuity and contrast sensitivity at all distances, in addition to high levels of patient satisfaction with visual quality. 


\section{ACKNOWLEDGMENTS}

This study was presented partly in "ASCRS Symposium on Cataract, IOL and Refractive Surgery and ASOA Congress on Ophthalmic Practice Management, 19-23 April, San Francisco, USA, 49, 2013" and presented partly in "30th ESCRS Annual Congress, April, San Francisco, USA, 49, 2013". Intraocular lenses were provided by VSY Biotechnology Incorporated. No financial support was provided by VSY Biotechnology Incorporated for this study. The associated article processing charges for this publication were funded by VSY Biotechnology Incorporated. All named authors meet the International Committee of Medical Journal Editors (ICMJE) criteria for authorship for this manuscript, take responsibility for the integrity of the work as a whole, and have given final approval to the version to be published.

Conflict of interest. Mehmet Baykara, Yonca Aydin Akova, Osman Sevki Arslan, Necdet Cinhuseyinoglu, Tamer Takmaz, Ahmet Gucukoglu, Yildirim Beyazit Usta declare that they have no conflict of interest.

Compliance with ethics guidelines. The study was conducted in accordance with the ethical standards stated in the Declaration of Helsinki, and all patients provided informed consents prior to the study. The study was approved by the Ethics Committee of the coordinator center which was Uludag University Medical Faculty, Bursa, Turkey.

Open Access. This article is distributed under the terms of the Creative Commons Attribution Noncommercial License which permits any noncommercial use, distribution, and reproduction in any medium, provided the original author(s) and the source are credited.

\section{REFERENCES}

1. Schmidinger G, Simader C, Dejaco-Ruhswurm I, Skorpik C, Pieh S. Contrast sensitivity function in eyes with diffractive bifocal intraocular lenses. J Cataract Refract Surg. 2005;31:2076-83.

2. Zelichowska B, Rekas M, Stankiewicz A, Cerviño A, Montés-Micó R. Apodized diffractive versus refractive multifocal intraocular lenses: optical and visual evaluation. J Cataract Refract Surg. 2008;34:2036-42.

3. Häring G, Dick HB, Krummenauer F, Weissmantel $\mathrm{U}$, Kröncke W. Subjective photic phenomena with refractive multifocal and monofocal intraocular lenses; results of a multicenter questionnaire. J Cataract Refract Surg. 2001;27:245-9.

4. Steinert RF. Visual outcomes with multifocal intraocular lenses. Curr Opin Ophthalmol. 2000;11:12-21.

5. Leyland M, Zinicola E. Multifocal versus monofocal intraocular lenses in cataract surgery: a systematic review. Ophthalmology. 2003;110:1789-98.

6. Elzawawi A, Osama I, Ahmed E, Mohamed S, Ihab O. Evaluation of the visual outcome of multifocal intraocular lenses in cataract surgery. In: Poster presented at AIOC Proceedings, cataract session II. Kolkata; 2010.

7. Can I, Bostancı Ceran B, Soyugelen G, Takmaz T. Comparison of clinical outcomes with 2 smallincision diffractive multifocal intraocular lenses. J Cataract Refract Surg. 2012;38:60-7.

8. Wang M, Corpuz CC, Fujiwara M, Tomita M. Visual and optical performances of multifocal intraocular lenses with three different near additions: 6-month follow-up. Open Ophthalmol J. 2015;9:1-7.

9. Montés-Micó R, Alió JL. Distance and near contrast sensitivity function after multifocal intraocular lens implantation. J Cataract Refract Surg. 2003;29:703-11.

10. Akcay L, Tutas Gunaydın N, Sayman I, Dogan O. Comparison of visual acuity and contrast sensitivity between aspheric monofocal and multifocal intraocular lenses. In: Poster presented at ESCRS. Paris; 2010.

11. Muñoz G, Albarrán-Diego C, Ferrer-Blasco T, Sakla HF, García-Lázaro S. Visual function after bilateral implantation of a new zonal refractive aspheric multifocal intraocular lens. J Cataract Refract Surg. 2011;37:2043-52.

12. Santhiago MR, Wilson SE, Netto MV, et al. Visual performance of an apodized diffractive multifocal 
intraocular lens with +3.00-d addition: 1-year follow-up. J Refract Surg. 2011;27:899-906.

13. Lubinski W, Gronkowska-Serafin J, Podboraczynska-Jodko K. Clinical outcomes after cataract surgery with implantation of the Tecnis ZMB00 multifocal intraocular lens. Med Sci Monit. 2014;20:1220-6.

14. Biber JM, Sandoval HP, Trivedi RH, de Castro LE, French JW, Solomon KD. Comparison of the incidence and visual significance of posterior capsule opacification between multifocal spherical, monofocal spherical and monofocal aspheric intraocular lenses. J Cataract Refract Surg. 2009;35:1234-8.
15. Woodward MA, Randleman JB, Stulting RD. Dissatisfaction after multifocal intraocular lens implantation. J Cataract Refract Surg. 2009;35:992-7.

16. Martiano D, Cochener B. Multifocal IOLs in the high myope, 6-year follow-up. J Fr Ophthalmol. 2014;37:393-9.

17. Vrijman V, van der Linden JW, Nieuwendaal CP, van der Meulen IJ, Mourits MP, Lapid-Gortzak R. Effect of Nd:YAG laser capsulotomy on refraction in multifocal apodized diffractive pseudophakia. J Refract Surg. 2012;28:545-50. 